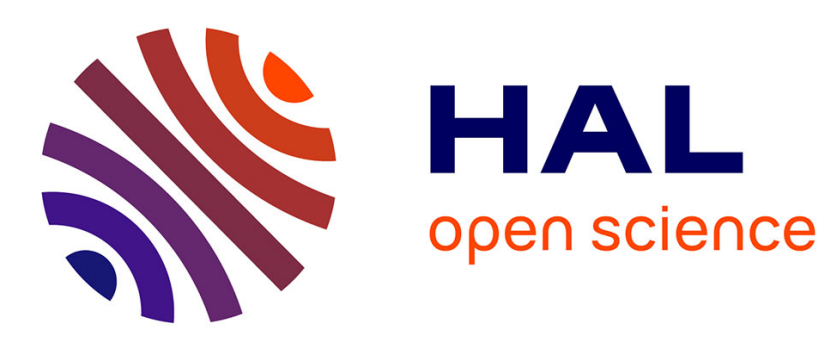

\title{
Citizenship and Consumption: Mobilisation in Alternative Food Systems in France
}

Sophie Dubuisson-Quellier, Claire Lamine, Ronan Le Velly

\section{To cite this version:}

Sophie Dubuisson-Quellier, Claire Lamine, Ronan Le Velly. Citizenship and Consumption: Mobilisation in Alternative Food Systems in France. Sociologia Ruralis, 2011, 51 (3), pp.304-323. 10.1111/j.1467-9523.2011.00540.x . halshs-00630238v2

\section{HAL Id: halshs-00630238}

https://hal-sciencespo.archives-ouvertes.fr/halshs-00630238v2

Submitted on 16 Jul 2014

HAL is a multi-disciplinary open access archive for the deposit and dissemination of scientific research documents, whether they are published or not. The documents may come from teaching and research institutions in France or abroad, or from public or private research centers.
L'archive ouverte pluridisciplinaire HAL, est destinée au dépôt et à la diffusion de documents scientifiques de niveau recherche, publiés ou non, émanant des établissements d'enseignement et de recherche français ou étrangers, des laboratoires publics ou privés. 


\title{
Citizenship and Consumption: Mobilisation in Alternative Food Systems in France
}

\author{
Sophie Dubuisson-Quellier,* Claire Lamine and \\ Ronan Le Velly
}

\begin{abstract}
Contemporary alternative food movement implement various means of action, which were previously developed by movements that were striving to construct citizenship through consumption. Drawing on the results of in-depth ethnographic studies, this article analyses the main fields of action of three French organisations: consumer education, implementation of alternative forms of trade and consumer mobilisation in protest campaigns. It shows that these actions require the movement to build representations of consumers, highlight their potential power within the framework of regulations and provide them with various tools to make the right choice. The article also presents the difficulties these organisations face in articulating political action and economic engagement. Consumption remains an important means for recruiting and mobilising individuals. Yet neither individuals nor movements can entirely overlook certain consumerist modes of functioning that stem from the current features of the agro-food system and the irreducible nature of the freedom of choice.
\end{abstract}

The history of the contribution of consumption and particularly of social movements around consumption in the construction of citizenship have been extensively documented by historians. During the American boycotts of English products in the eighteenth century the market appeared to be a space for the construction of identity and citizenship of a nation seeking its independence (Breen 2004). Consumer mobilisation became regularly seen as a way to demand new social rights. In some instances these rights concerned the social groups with which engaged consumers displayed their solidarity, as in the case of the US abolitionist movement in the nineteenth century, which organised the sale of slavery-free products (Glickman 2006). The US national consumers leagues and the social consumers' leagues in Europe, created in the early twentieth century, likewise made consumers aware of the shameful labour conditions in certain workshops. In the first half of the twentieth 
century the American Federation of Labor systematised this approach by publishing blacklists of firms whose labour practices it denounced.

In some cases social groups defended their own rights through their economic power. Certain co-operative movements, especially the British and US movement born in the mid-nineteenth century (Furlough and Strikwerda I99I), can be interpreted as the endeavour by middle-class women to use the market to secure the status of citizenship that society denied them by refusing them the right to vote. More recently Black American movements, created to fight for social rights, frequently resorted to boycotts and 'buycotts' to assert their integration into American society (Cohen 2003).

Most of the mechanisms on which the collective approaches of contemporary consumer-oriented movements are based can be likened to those of the older movements. For example, the principle of the construction of distant solidarity between consumers and another social group, found in contemporary fair trade movements (Raynolds 2002), were already in existence in abolitionist movements as well as in campaigns to promote products of the Empire, organised by the British Women's Patriotic League in the I920s (Trentmann 2007). In these two movements the idea was to enable consumers to associate products with the issues pertaining to the place and conditions of their production. Likewise, the contemporary principle of consumer responsibility, expressed through the integration of new citizen's duties concerning collective environmental issues, brings to mind the context in which certain governments in the USA (Cohen 2003) and the UK (Trentmann 200I) highlighted consumer's obligations with regard to the war effort or post-World War II reconstruction (Daunton and Hilton 200I). We therefore need to consider contemporary movements in relation to this history if we wish to explore the forms of articulation of the citizen and the consumer, as proposed by the movements that we are studying.

Three main directions for consumer mobilisation can be identified in these former movements. The first originated with the co-operative movements and was aimed at involving civil society in economic regulation. The second was oriented towards the construction of citizenship for minorities; consumption was a means to the end of citizenship. The third was dedicated to the construction of a sense of consumers' duties with regards to the functioning of markets; consumption was a means to include civil society in the market regulation process. Contemporary alternative food movements follow these different traditions even though they do not explicitly refer to them.

This article intends to demonstrate that consumption is the means that alternative food movements use in their endeavour to get citizens to be more active in the negotiation of economic regulations. To do so they build a representation of the consumer, highlight their potential power within the framework of regulations and provide them with various tools to make the right choice.

An in-depth ethnographic study on three alternative food activist groups in France allowed us to identify the different ways to mobilise consumers in the negotiation of a food system. The first of these organisations is the Fédération Artisans du Monde (FADM), one of the pioneers of fair trade in France and currently still the main French network of shops specialised in the sale of fair trade products from the countries of the South. In 2008 the FADM network comprised $\mathrm{I}_{5}$ local groups composed 
essentially of voluntary workers and, in many groups, one employee. The FADM also develops educational tools that its members can use to raise awareness in the general public or in schools.

The second group was formed in the early 2000s around the Associations pour le Maintien d'une Agriculture Paysanne (AMAP), along the lines of the US Community Supported Agriculture model. By 2007 it consisted of 500 local consumer groups. These consumers enter into medium-term contracts with one or more producers who undertake to supply them with a weekly box of fresh organic farm produce. The aim of this reciprocal commitment is to guarantee the viability of the farms concerned and to establish an equitable relationship between producers and consumers. The third group, formed around the non-profit organisation ConsoResp, ${ }^{\mathrm{I}}$ stemmed from the French anti-globalisation organisation ATTAC. The organisation was founded in $200 \mathrm{I}$ with the aim of making consumers aware of their responsibility in the deterioration of the environment and problems of social injustice. This activist group, which is smaller than the former two, is one of the rare social movement organisations in France to promote political consumerism.

These three militant groups all target consumers whom they wish to mobilise around the causes that they are defending: support for producers in countries of the South, in the case of FADM; the struggle against economic globalisation in the case of ConsoResp and the maintenance of small-scale farming in peri-urban areas, in the case of the AMAPs. This support by consumers is expected to materialise in the form of new consumer choices that include new priorities and demands concerning products and production systems, as well as a militant engagement by these consumercitizens.

The three groups that we have studied implement a wide range of actions which, in reference to theories of social movements (Tilly 2006), can be classified into three main repertoires of protest, in the sense of tactical actions with a protest dimension, an intention and the construction of a collective identity (McAdam et al. 200I; Taylor and Van Dyke 2005). These three repertoires are: consumers' education; their engagement in alternative forms of trade to the conventional market; and, finally, their mobilisation in protest campaigns. All three organisations use these three forms of consumer mobilisation but each one seems particularly dedicated to one of them.

Our results are drawn from qualitative data that we collected and analysed. We conducted three field surveys on the militant groups studied, consisting of interviews with the heads of these organisations, a biographical analysis of the militants' trajectories and the ethnography of the various spaces of negotiation and decision-making in the militant groups and an analysis of the various documents drawn up and disseminated by them. As some activists belonged to two or even three of these groups we were able to study both their singularities and the common points in their discourses and militant repertoires. Finally, we interacted with the groups, to whom we submitted our analyses, and this was often an opportunity to identify their reflexive capacity with regard to their practices and their representations of the consumer's role.

In this article we present these three kinds of consumer mobilisation and define the consumer roles that these movements set out to build. In the conclusion we describe the difficulties they face in their attempt to mobilise consumers through one 
type of role. We show that the main pitfalls encountered by these movements lie in the difficulty of linking political action to economic engagement. Consumption remains a key tool for recruiting and mobilising individuals, precisely because it is a means to actually put into practice one's social conscience. Yet neither individuals nor movements can entirely overlook certain consumerist modes of functioning that stem from the irreducible nature of the freedom of choice.

\section{Enlightening and educating the consumer}

Unlike certain French movements specifically oriented towards educating the public, consumer education is not the main mission of the three movements studied here. It is nevertheless one of the keystones of their mobilisation and of the construction of an identity. The aim is primarily to anchor consumers' feeling of responsibility in the evidence of their unwitting or involuntary contribution to certain global disorders. Echoing former movements such as American or European Consumers' Leagues from the end of the nineteenth century, they want to reconnect consumers to certain issues concerning production, such as working conditions. In particular they insist on the moral and political dimensions of individual choices, which have collective effects. These choices can, for instance, either improve workers' conditions or worsen them. But for this connection to be made, the consumer must be informed about the working conditions or other similar issues.

The idea of educating consumers is based on a specific conception of their role in the political economy. It implies making them active players and experts, able to wield their economic power in the market. As consumers' leagues used to do, the movements that we analysed try to appeal to consumers' individual consciousness in order to build up their economic power. Even if the three organisations on which we focused use the rhetoric of consumer education, FADM is the group with the most formal tool in this respect. The tradition of consumer education is totally congruent with fair trade operators' strategy of using the market as a way to help small producers from the South and to exert pressure on governments and international institutions in order to change the market rules. The responsible consumer becomes the main player in this process, making the market more permeable to new players, new rules and new values. The rhetoric contained in the various actions implemented by these movements articulates three dimensions: the first concerns the manipulation of consumers and the frequent contradictions between the values they claim to have and what they actually do in practice; the second pertains to the disclosure of certain modes of functioning of conventional agro-food systems; and, finally, the third aims to equip consumers with new references in the marketplace.

The consumer without conscience: from the manipulation theory to the couch potato criticism used by movements

In the three organisations we find, in various forms and to differing degrees, a consumer role relatively similar to the one produced by critical sociology in the I 660 . The Frankfurt School showed how the advertising industry manipulates the consumer, substituting a mass consumption culture for popular culture (Adorno and 
Horkheimer 1974). Marcuse also used this argument to demonstrate the dependency of the consumer on mass consumption (Marcuse I968). Baudrillard systematised this analysis by insisting on the disconnection between use value and exchange value, emptying products of their substance and transforming them into signs of identity (Baudrillard 1968). The main idea of the manipulation of consumers by the various market professionals, such as marketers, advertisers and the media, stresses the principle of the opacity of the market, preventing the consumer from being a real player in the market or at least from being conscious of how it really functions.

In the rhetoric of the activist groups, consumers are presented as victims of a general scheme to manipulate them, in which their own aspirations are confused with the desires that the mass consumption society nurtures in them. They try to make consumers feel responsible by showing them the reasons for their irresponsibility. The standpoints of FADM, the AMAPs and above all ConsoResp highlight the themes of manipulation of consumers and the need for them to feel responsible. Consumers appear as both victims and culprits. The argument of guilt allows the activists to emphasise the risk of immobility: in their discourse, consumers are portrayed as couch potatoes who absorb all the messages of the mass consumption system without any criticism. Consumers are therefore urged to disengage themselves from this situation, largely ascribed to all the techniques and commercialisation mechanisms that draw them into a consumerist spiral exceeding their needs, and to stop being manipulated by advertising, as suggested by French anti-advertisement groups (Dubuisson-Quellier and Barrier 2007). The activist groups emphasise consumers' contradictions between their displayed intentions regarding respect for the environment or defence of social justice and their actual consumer practices.

\section{The disclosure of the functioning of food systems}

The plan to educate consumers also involves an approach designed to reveal the functioning of globalised food systems. The activist groups start with addressing and informing their members, as in the case of the AMAPs that often organise discussions at their meetings on the topic of consumer engagement. But they are also oriented towards the general public, and local or regional AMAP events are an opportunity to spread this message outside the network. An example, on the scale of a single AMAP, is the Circuit court ${ }^{2}$ festival articulating debate on the solidarity economy, the projection of a film denouncing industrial agriculture and a picnic on a Provençal farm (February 2008). On a larger scale, regional AMAP festivals are organised as well, such as the one in March 2007 in Marseilles, attended by about one thousand people. FADM and ConsoResp also participate in many public events enabling them to inform the public and to emphasise the nature of the social relations hidden behind the relationships between products (Hudson and Hudson 2003). ConsoResp constructs a large part of its critical repertoire against the modes of functioning of mass distribution. It shows that firms, while pretending to defend consumers' buying power by negotiating low prices with their suppliers, exert power over the market in three respects: power over producers and especially the most marginalised who cannot meet the demands of mass distribution; power over employees, who are subjected to the constraints of temporary and often forced part-time 
work; and, finally, power over consumers, who have access only to the products that big firms decide to sell.

ConsoResp and FADM specifically target schoolchildren. For example, during the solidarity breakfasts organised by FADM, primary-school children are made aware that behind their breakfast foods, such as chocolate or sugar, there are people who work and who live, sometimes with difficulty, from that work. Actions catering for high-school pupils describe the functioning of the branches of what fair trade activists call 'conventional trade'. They emphasise the recruitment and labour conditions of workers on plantations belonging to multinationals and the low prices that small producers obtain from local agents to whom they sell their produce. ConsoResp, firmly convinced, like FADM, of the necessity to inform the youth, has designed a specific tool called the educational kit. This kit is designed to inform high-school teachers about sustainable development and focuses mainly on consumption: from reading labels to highlighting the interests of stakeholders in complex issues (such as the regulation of genetically modified organisms GMOs or crises in the fruit and vegetable sector).

\section{Equipping the consumer with new market References}

Once consumers feel responsible for their actions they are urged to make good choices. The activist groups try to provide them with the data and references necessary to find their way through the offerings of the market. This may be done directly through the creation of specialised shops, as in the case of FADM which group together an alternative offering. In that case, as we see later, the equipping of the consumer takes the form of a turnkey mode of political action, affording ready-made opportunities to act in favour of the values espoused by fair trade. This implies that a specific effort is made to bring to light the effects of this type of trade.

The aim of the information offered in shops is not only to inform but also to demonstrate the specific nature of fair trade and its associated benefits; in other words, to generate sources of trust in the system, without which consumers would not alter their consumption habits. The use of a rhetoric based on simple messages in which the conventional is contrasted with the fair, or the before with the after, also clearly reflects the sometimes deliberately oversimplified nature of the messages transmitted (Le Velly 2006). The prevailing argument is the aggregate and collective effect that is inevitably produced by these combined individual involvements. This goal of making the consumer more of an expert in the market may also be achieved more indirectly, for example, when ConsoResp appeals to consumers to be vigilant and attentive. The idea is precisely to depart from the automatic, routine attitude that the group attributes to consumers. It accuses them of relying on the diverse signals of market intermediation such as labels and brand names, without looking more closely at what underlies them. ConsoResp's intention is to highlight the fact that labels fail to give the complete truth, because they say little about some of the aspects of choices made by food producers. Actually, one of the main hypotheses made by the group is that most of the market signals are designed for mass markets: in a way they largely contribute to maintaining consumers' ignorance of the choices that have been made and the realities behind the products. The organisation's role is then to help 
consumers to find their way in this new alternative market space - clearly opposed to the mass market - which it promotes on its website or in public discourses. In 2003 it published a guide to responsible buying for consumers in an area north of Paris and is currently working on the preparation of a generic guide designed to enable each area to produce its own local guide.

The AMAPs also wish to guide consumers by building partnerships with other forms of ethical trade (fair trade, farm markets), based for example on the participation of an AMAP producer in a farmers' market, or on the distribution of boxes of produce in fair trade shops. In a way, the AMAPs also rely on the aggregate effects of individual acts. They now have over 500 groups and a membership estimated at some I००,००० individuals. In many cases they have extended their box of fruit and vegetables (or meat or other products, in some instances) to a range of local farm produce. Yet the aggregate effect is perhaps not as central for the AMAPs and for ConsoResp as it is for FADM, as there the rhetoric focuses mainly on the mutual commitments between farmers and consumers on a local scale.

In summary, enlightening and educating the consumer implies the need to set individual acts of consumption in a more collective and societal context and to urge members to have a far more critical attitude towards their consumption choices and the implications of these choices. In other words, the political dimension of these consumer engagements lies both in the economic power produced by the aggregation of individual acts (Micheletti 2003) and in the political strength of a consumer movement capable of reorienting individual concerns in a more collective dynamic. However, explaining and decrying the market mechanisms that cause consumers to act irresponsibly is not enough. It is also necessary to implement systems of trade in which a new consumer responsibility can be expressed.

\section{Concretely engaging the consumer in trade}

The three activist groups under consideration are all set in the current dynamic of alternative food systems (D. Goodman 2002, 2003, 2004; Goodman and DuPuis 2002; Whatmore 2002; Watts et al. 2005). Most of these systems not only criticise conventional food suppliers for their negative externalities on the environment or social justice (Allen et al. 2003) but also offer concrete alternative forms of trade. The FADM founded in the I970s was the first systematised fair trade initiative in France, while the mission of the AMAPs, born in the early 2000s, is to organise long-term contracts between producers and consumers around the supply of food products on the basis of geographical proximity. ConsoResp was not founded with the aim of implementing a trade system, yet a few years after its creation some of its members undertook to organise a short demand-supply chain system. To varying degrees, these different schemes have made the consumer's engagement in specific and ad hoc forms of trade one of their main forms of mobilisation.

\section{The implementation of ad hoc forms of trade}

In the case of FADM shops, the offer available to consumers is the outcome of a series of commercial market channels involving numerous different actors 
(Whatmore and Thorne I997). All these channels are built upstream from the act of purchasing and the consumers participate neither in the selection of producers, in the negotiation of purchasing prices nor in the definition of the criteria governing practices. Moreover, even though at the beginning of the FADM movement the activists in shops had maintained direct relations with groups of producers in the South, for the past two decades importers specialising in fair trade have taken over that role (Le Velly 2007). Hence, even though the success of fair trade initiatives depends on consumers' participation through their acts of purchasing, consumers play no part in the construction of the commercial relations preceding their purchases. In this respect, citizen consumption offered in fair trade shops is, as Michael Goodman (2004) put it, far more consumer-dependent than consumer-led.

The same does not apply to the AMAPs, since in their case the trade network is generally started by a group of consumers that is formed first, before making contact with producers who could supply the weekly box on which the system is based. In this case, unlike that of FADM, consumers play an active part in building the commercial relationship and determining the contents of the box. In this sense, of the three schemes, the AMAPs best represent the implementation of alternative ad hoc forms of trade. The terms of trade are negotiated directly between consumers and producers, even if this negotiation is often limited and varies widely from one group to another. These negotiations are particularly effective when there are problems, for instance in cases where the producer has major difficulties (pests, crop failure or labour problems). In certain AMAPs that are not involved with organic farming, the most interesting negotiations can be observed around crop protection practices. In one of the cases studied, the producer warned consumers of the invasion of weeds in one of the fields. Since they refused to use herbicides and other techniques were too timeconsuming for the producer, the consumers decided to weed the field themselves, manually. Finally, unlike fair trade shops and the third case discussed below, the AMAP system is based on the idea of a supply that is as complete as possible. The quantity of vegetables in the weekly box is calculated so that theoretically the consumers do not need to buy elsewhere.

The organisation ConsoResp tries to promote alternative systems. It actively supports the AMAP scheme by frequently relaying information about it, inviting its members to participate in its debates and citing the model as an example. It also defends certain fair trade approaches, especially those of FADM, as opposed to initiatives that it deems to be too close to conventional market mechanisms. The leaders of the organisation strongly encourage members to join these networks and a very large proportion is effectively active in them.

Strongly inspired by the AMAP model, some of the more active members of ConsoResp have also felt the need to put their convictions into practice. In 2004 some families decided to get together to set up a system of procurement from a farmer in the organisation. The network, called Alter Conso, has grown consistently over the years. The 50 or so Parisian families involved have organised themselves into I4 groups, in which orders and deliveries are centralised around a host. The producer has managed to enrol other farmers and has created an economic interest grouping consisting of I5 producers who supply diverse organic products. 
The network is large in geographical terms, which does not enable it to be an AMAP since the producers are situated some $300 \mathrm{~km}$ from the consumers. But the supply chain is short from the point of view of intermediation since the consumers can be in direct contact with one another. Moreover, the farmer often travels to Paris anyway for his militant activities. Unlike an AMAP, produce is supplied on a monthly rather than a weekly basis, so that consumers sometimes need to shop elsewhere. Finally, like many AMAPs, the members of this system of family supplies try to arrange encounters between consumers and producers, mainly by organising annual events at which issues concerning producers are debated, for example the situation of small farmers, organic farming, or GMOs. In so doing, these activist groups aim not only to open new spaces of negotiation between consumers and producers, thus embedding individual acts of consumption in a more collective reflection, but also to create opportunities to involve consumers in the public debates from which they are often absent.

\section{The role of the alternative consumer}

The AMAP scheme and ConsoResp allow consumers to move into new spaces of negotiation with the producers of their food. In the AMAPs, the terms of the contract between producers and consumers are negotiated on the scale of a local consumer group. When an AMAP is created and at the beginning of each season, these negotiations concern the content of the box (number of different vegetables, quantity and choice of varieties), the mode of production (organic or not, certified or not) and the price of the box. However, the negotiations are to a large extent framed by the network, the tools that it provides and other similar groups or organisations (Dubuisson-Quellier and Lamine 2004).

The cases of the AMAPS and Alter Conso, in which consumers are involved in the organisation of alternative systems of trade and participate in debates with producers, highlight the differences between them and the FADM proposals. The political involvement through consumption offered by the latter is closer to what could be called a turnkey mode of political action, affording ready-made opportunities to act individually for the causes associated with the products concerned and it differs from the more deliberative mode offered by the other two groups. FADM leaders are mostly aware of this difference and some of them, inspired by the AMAP model, have begun to seek ways of involving their consumers, or at least their volunteers, more directly in the governance of the relationship with producer organisations in the South. However, apart from this significant difference, the three activist groups we studied share the idea of articulating the denunciation of conventional market mechanisms and the demonstration of the viability of alternative solutions.

In this sense they are close to some of the ideas of the co-operative systems in the late nineteenth century, which also proposed concrete alternative solutions to organise a form of trade aimed at directly linking producers and consumers and at avoiding intermediaries. Like those early co-operative movements, contemporary activist groups try to foster deeper involvement by consumers and, more generally, civil society in the making of economic rules so that they are not influenced only by the state and private companies (Furlough and Strikwerda I99I). In both cases, 
consumption becomes a way to educate consumers and appears more as a means than as a goal to build citizenship through ordinary practices. Consumers can thus become more aware of the difficulties and constraints of small producers and of the effects of some choices, such as asking for counter-seasonal production. But this awareness not only aims at changing individual patterns of consumption; it also needs to involve consumers in political and often local debates about collective choices. Some AMAPs contribute actively to local debates and actions concerning environmental land-use issues, for instance. South of Paris, one of them initiated the creation of a specific organisation for collecting funds from local inhabitants and civil society to buy land threatened by urbanisation and make it available for sustainable agriculture and local alternative food systems. Some AMAPs also collaborate with local public authorities that lend pieces of public arable land to landless farmers, who then supply the local AMAPs.

The political dimension of these activist groups lies in their capacity to collectively mobilise consumers in the local negotiation of choices of production (or even, as in the case described above, in negotiation on land use and property) and in specific protest campaigns organised or followed by the groups. From this perspective, the concrete alternative forms of trade they build can be described as a space for the possible recruitment of individuals prepared to engage in collective and political action.

\section{Mobilising the consumer in protest campaigns}

Campaigning activities are not central for all three groups. ConsoResp has the broadest scope in terms of repertoires and sees campaigning as one of its major activities. The activist groups' involvement in protest campaigns and the nature of their actions also depends strongly on their scale of action (local, national or global).

\section{Different organisations, targets and political positions}

Our three groups have different ways of organising their members' participation in forms of political action in the public sphere and especially in protest campaigns.

Their organisational structure often strongly determines the nature of the militant actions developed. ConsoResp, established in Paris, has difficulty structuring local groups and is better equipped to undertake national actions and even to link with other national or international organisations. On the other hand, the AMAPs, which are local groups, are rallied more easily to local actions but have difficulty in participating in national or international debates. Finally, FADM operates on two scales: that of its shops and their local networks; and that of the Federation, which is present in most national and international debates on global trade issues.

The targets of the actions are also different. ConsoResp and the FADM engage their members and sympathisers to appeal both to the public authorities, in order to change existing regulations and to certain private companies, in order to change their practices. The AMAPs are less directly involved in this type of action but very often support information campaigns or lobbying launched by similar organisations.

Finally, the political positioning in relation to public action also varies. FADM and ConsoResp have the same approach in urging government authorities to regulate 
trade. Several opinion columns have been published by ConsoResp denouncing the weakness of government intervention in three main areas: the regulation of agro-food products; the regulation of corporate labour practices; and the organisation of forms of participatory democracy. The first includes protest over the cultivation of GMO plants in France, over the transcription into French law of the European directive on organic farming and over the lack of sufficient control of the ionisation of foods. Lying behind this demand for government regulations is the organisation's claims that dominant economic actors, especially multinationals, will make real changes only if compelled by law to do so. The FADM has likewise invested in various campaigns aimed at challenging the behaviour of certain economic players and altering the regulations on the agro-food system. Examples include actions recently undertaken against the exportation of cheap European chickens to Africa, or the massive importation of South American soy - two commercial practices accused of profoundly destabilising peasant farming worldwide.

\section{The role of the consumer citizen}

Within this framework, ConsoResp and the FADM propose various tools for people wishing to participate in their action. Most of these are cognitive, involving information produced by the two groups or disseminated by them through various channels (such as websites, e-mails, posters, pamphlets and conferences). Consumers, furthermore, have the possibility of signing petitions and sending standard letters.

Whereas certain consumers who belong to these schemes see engaged consumption as a substitute for more traditional forms of political action, other members and the groups' leaders see it as complementary to more classical acts of political mobilisation. This articulation is at the heart of ConsoResp's militant action in which it encourages consumers to engage in alternative networks and appeals to economic and political actors via public campaigns. This logic of complementarities also appears to be central for FADM, for several reasons. First, it is expressed in the targeted effects, since the aim is both to build alternative trade systems and to alter the functioning of the conventional market. Second, the actions are conceived of as having complementary goals: since only a minority of producers can benefit from fair trade, other modes of action need to be deployed. Finally, for some FADM activists, complementarities are expressed from a perspective of raising consciousness. The fact of selling in shops is seen as a way of prompting consumers to think about the functioning of the world in which they live. The purchase of a fair trade product is supposed to be able to trigger a sudden awareness, leading to reflection on less equitable forms of trade and to a wish to be informed about the dysfunctions of international food systems. Political consumption and more classical acts of political mobilisation are at the heart of the AMAP project, a tool used to make consumers aware of the functioning of food systems and the conditions of players further upstream in the process. Common to all these activist groups is the determination to build up their members' awareness as citizens, based on direct involvement in forms of consumption that enable them both to put their political commitment into practice and to be able to engage in collective forms of action. 
The groups' involvement in protest campaigns, especially in the case of Action Consummation, nevertheless contributes to promoting an ideal of the consumer citizen which is noticeably different from the former roles of the enlightened consumer and the alternative consumer presented above. The idea is to re-engage citizens in collective life by asking them to put new issues about food, market regulation, environmental and ethical issues on the public agenda. Consumption appears to be the pivotal area where citizens can develop their capacity to address these issues and demand improvements in public regulations. This position is closer to that of social movements such as the civil rights movements which, during the first half of the twentieth century, advocated the rights of certain groups of citizens. Many of these movements, such as the National Association for the Advancement of Colored People that organised the 'Don't buy where you can't work' campaign for Black Americans, used consumption as a way to involve citizens in their protests for civil rights (Cohen 2003). Many years earlier, the late seventeenth century protests and boycotts against English products had contributed to establishing the concept of solidarity in the USA (Breen 2004). Conso Resp and, to a lesser degree, FADM, try to involve consumers in the negotiation of their rights, as citizens, to participate in deliberative processes on various issues concerning them: what type of agriculture should be promoted by the state? What importance should big retailers have in the distribution of food? How to protect scientific whistleblowers from legal proceedings if they contribute to identifying new risks for citizens? The main difference between them and the previous movements is the idea that these rights are peculiar not to an ethnic or national group but to a social group that is, consumers.

The promoters of these forms of engagement around consumption face real difficulties, related mainly to the tensions that sometimes appear between the different trajectories open to consumers in each group. Most of these trajectories create tension between the consumer and citizen roles and generate critical debates within these groups.

\section{The limits of consumers' modes of engagement in alternative food systems}

Studies on sustainable consumption (Spaargaren and Martens 2004), political consumerism (Micheletti 2003) and food democracy (Hassanein 2003; Wilkins 2005; Levkoe 2006) have emphasised the role of the articulation between the citizen and consumer roles in the implementation of public action for effective sustainable development. What is the capacity of the groups that we are studying to articulate political and market roles and what difficulties do they encounter?

The first difficulty is related to the plurality of consumers' trajectories in their engagement in these movements. The second stems from the problem of entirely breaking free from the consumerist logic expressed in the activists groups.

The plurality of consumers' motives for engagement

Individuals join the groups that we have studied for very different reasons, ranging from the pursuit of individual aspirations to collective and highly political engagements (Dubuisson-Quellier and Lamine 2004). These differences can sometimes 
lead to difficulties within the groups. All three activist groups have members from different backgrounds who express varying degrees of activism and sometimes even display no political engagement at all. The organisations therefore have to come to terms with this plurality of trajectories, as do most social movements. But the special character of the rifts produced by this diversity here consists of the forms of opposition between what are thought to be citizen engagements and a logic that could prove to be still too consumerist.

In the case of the AMAPs, we can identify three main forms of engagement, corresponding to three views of the box of produce supplied. For the less engaged individuals, the box represents, above all, an original mode of buying healthy and tasty products. These Amapians are not necessarily particularly interested in the producer or in issues of responsible consumption in general. They often first contact the AMAP out of a concern for their health or an interest in this alternative form of consumption. Others see the box as an original form of trade with a family farmer. Their engagement lies mainly in the development of interpersonal relations between consumers and producers; they are interested in local consumption and a neighborhood relationship in the AMAP, above all. Finally, for the most engaged consumers, the box is both an engagement to support farmers and an act of citizen consumption relative to the broader concern for the future of the agro-food system. This naturally corresponds to the group's view.

In the case of FADM, a rift can be observed within the group, often pointed out by activists in the organisation themselves, between on the one hand those interested mainly in selling fair trade products and, on the other, those more engaged in an educational approach and in campaigns. In terms of personal profile and motivations, the differences between the two groups are noteworthy. The voluntary workers, who mainly wish to work in the shops, tend to be older than the others (many are retired) and see this occupation as an opportunity to defend a cause, to fill their spare time and to develop social relationships. They consider the sale of fair trade products to be a real way of supporting small producers. Often they find the Federation's advocacy campaigns difficult to relay because of the complex economic and political issues involved. In contrast, the voluntary workers who are more engaged in advocacy and education tend to judge - sometimes severely - the 'afternoon grannies' whose view of fair trade they see as excessively charitable and insufficiently political. Thus, even if FADM tends to highlight the complementarities between selling on the one hand and education and advocacy on the other, implementing these complementarities in a group is not necessarily straightforward.

This difference is also felt at ConsoResp, even if the activists' profiles are less heterogeneous than in the other groups. The most active members accuse the others of using the organisation only to obtain information for their own individual consumer choices. Even though, as in the AMAPs, the organisation's goal is above all social and alter-globalist, it is also mingled with strong ecological concerns, promoted by activists who joined more recently. Today the organisation has around Io० members, of which only about to are particularly active and participate in the life of the organisation. The members' profiles vary widely, but most were involved at an early age in associative or sometimes professional networks. The most engaged members often have to make trade-offs between the different collectives to which they 
belong to be able to manage the time devoted to these causes. This makes it even more difficult for ConsoResp to identify available resources for a particular action.

The three groups all highlight the difficulties of mobilising through collective action: manning the organisation's stand at various events; participating in collective events; giving talks or briefings; and, for the AMAPs, participating in the actual functioning of the system. The members' expectations of their organisation vary. Some are mainly interested in specific resources for their families or themselves: information on engaged consumption, for most ConsoResp members; social relations around a cause for certain voluntary workers at FADM; fresh, good quality produce for certain Amapians. Others choose to grasp the opportunity for more collective action that implies strong mobilisation. They are seldom satisfied with the other forms of engagement, deemed to be too individualistic and above all insufficiently politicised, possibly because they are too close to a consumerist logic.

\section{How to get rid of consumers and replace them with citizens?}

Questions concerning an overly consumerist logic also structure a series of debates within these groups on the collectives' capacity to alter consumers' choices. In view of the organisation of alternative forms of trade and supply channels, the collectives considered here examine in very practical terms the nature of their offerings, their range and their price. On these two points the approaches of FADM and the AMAPs both indicate that market realities and the dominant consumer logic cannot easily be disregarded. The propensity of these systems to generate new forms of demanddriven trade is therefore questioned, as is the alternative character of the approaches implemented.

Hence, the market dimensions of alternative networks prompt their members to examine some of the questions usually raised about trade. For instance, quality and price have to be envisaged as possible dimensions of a match between products and consumers. But in these particular networks, where the aim is political action and not only trade, questions of this nature are more specifically related to political choices and therefore trigger debate within the scheme.

The question of quality, for example, has been raised in both the AMAPs and FADM to examine the possibility of these groups opening up to more marginalised producers. Noting, in an impact study, that the producer organisations working for its network are not the most marginalised (Mestre 2004), as scientific research has also shown (Littrell and Dickson I999; Murray et al. 2003), FADM activists have wondered about the level of quality that should be demanded from producer organisations. The question whether it is possible to reach small producers who are unable to find outlets in the conventional trade system while still offering quality products that meet consumers' standards has likewise been raised in the AMAPs. In some cases AMAP consumers have either accepted boxes with few products for a short while to support a producer who is starting up or has had particular difficulties, or else have severed the trade relationship with the producer. Some groups have also debated the need to broaden the range of products in their boxes, to ensure that consumers are satisfied, even if this means adding products such as citrus fruit not grown in the area. More generally, the question is also whether consumers' quality criteria should be 
treated by these networks in the same way as for any market system or if they should be collectively redefined with the players upstream or in relation to those players' requirements and challenges.

The difficulty of disregarding usual consumption logic in the construction of alternative systems applies fully to the question of price. The activists of both FADM and the AMAPs demand fair prices between the different links in the chain. Above all, the aim is to guarantee remuneration enabling producers to cover their costs, to live properly from their work and to be rewarded for their efforts. In the fair trade food supply chains established by FADM, the prices paid to producers are aligned with the international fair trade standards defined by Fairtrade Labelling Organizations International (FLO). In the mid-20oos FLO worked on determining a way of calculating fair prices that would take into account production costs, costs of conversion to fair trade criteria, living costs and the profits needed to implement development projects. It was nevertheless unable to define such a formula due to the technical complexity of such calculations that had to be defined individually for all the products and regions concerned and probably also due to the impossibility of totally disregarding the prices used in conventional trade systems (Le Velly 2007). In the case of the AMAPs the price of a box is usually set in relation to the box prices of the closest AMAPs and/or market prices (Lamine 2005). Finally, in the case of ConsoResp, the organisation had to give up trying to set a price exclusively on the basis of production costs to avoid competing with a local co-operative shop. Thus, notwithstanding political ambitions aimed at extracting these networks from market functioning, the practical reality is far less clear-cut. Market prices, like certain consumer preferences, sometimes remain a compulsory reference for promoters of the alternative supply chains studied.

This raises the question of the role and, more precisely, the power of consumers in these alternative networks. The forms of power existing in fair trade have been examined in the literature, which highlights the maintenance of a form of domination by consumers over producers (Renard 2005; Shreck 2005). The fact that, until now, the norms concerning conditions of production and price levels have been determined largely without representatives of producer organisations also suggests that these fair trade supply chains are dominated by demand (Daviron and Ponte 2005). This perspective can be applied to the case of the AMAP, where the principle of consumers' contribution to the governance of the system is immediately perceived as democratic and conducive to the achievement of their objectives. Yet part of that argument does not hold up, in so far as some consumers may not enthusiastically embrace it (some prefer not to go to the farm or not to acquire knowledge about farming and its constraints) and in so far as this type of governance is not exempt from new forms of demand-driven trade more or less well tolerated by producers. Some producers may perceive consumers' participation in their decisions as interference in their work. In one of the AMAPs studied, for instance, a producer preferred to start a new group where the consumers made fewer decisions, whereas the group's ideal is to rebalance the power of decision-making between producers and consumers.

The AMAPs can indeed become structures in which consumers have most of the decision-making power and the producers become their suppliers. If their production 
is sold entirely through the AMAPs, producers can fear they might be compelled to meet consumers' demands just as they were formerly forced to comply with the terms and conditions of mass distribution on which they relied to sell their products. Are we witnessing here the creation of new forms of farmers' subjugation under cover of what is supposed to be support for peasant farmers? This would be particularly problematical for the AMAPs, as one of their basic principles is autonomy, that is, the ability of farmers to make their own choices and to be less dependent. It is also striking that ConsoResp tends not to take a stand in this type of debate. We could posit that the organisation envisages the participation of consumers in these alternative systems less in the form of shared governance with producers than as support for their initiatives. Closer to a concept of citizen governance and participative democracy, it considers that consumers' power has to be exercised above all through appeals to public and private actors and involvement in local public life.

The difficulties that these direct networks between producers and consumers face in balancing the ways in which power is exercised may suggest the limits of a system without an arbitrator where producers can be put back-to-back with consumers whose interests differ, as is sometimes the case in conventional demand-supply chains.

\section{Conclusion}

Research on alternative food systems has strongly emphasised that they offer consumers new access to spaces of co-production (Holloway and Kneafsey 2004), enabling them to negotiate with producers on some of the specific characteristics of products or even of production systems (Dubuisson-Quellier and Lamine 2004; Lamine 2005). These studies have also contributed to the description of consumers' individual engagements in local networks, which enable them to link their choices to political projects (Goodman and DuPuis 2002). These networks, often perceived as hybrid assemblies of actors and objects, then become the loci of expression of different forms of agency, where that of the consumer plays an important part (Whatmore and Thorne I997; Goodman 2002; Lockie 2002). We have ourselves emphasised the dimensions of consumers' empowerment in these alternative networks (DubuissonQuellier and Lamine 2008), to highlight the new negotiation capacities that they can acquire through local forms of governance around food systems. Without necessarily considering that consumption replaces apparently declining forms of political expression, the idea is to see how consumers envisage individualised (Micheletti 2003) or openly collective forms of political action through their participation in these alternative food systems.

In this article we have explored the ways in which these consumer political engagements, often understood as the construction of a new food citizenship, could replace the consumer role with that of the consumer citizen. As we have shown, the complementarities of these two positions - political and economic - between the consumer and the citizen entail certain problems. The activist groups are confronted with the fact that freedom of choice is irreducible and may be expressed in these systems in a way that is not entirely different from conventional systems. Consumers can have preferences concerning the variety of the offerings or wish to practice forms of demand-driven consumption that may not always be compatible with their 
organisations' political positions. This limit indicates that the effectiveness of these groups' militancy lies less in their capacity to spread their message to the masses the scope of this article has not allowed us to discuss the fundamental issues of social equity and social accessibility of alternative consumption - than in their daily work on the capacity for articulation between collective political aspirations and individual consumption habits.

Based on the empirical observation of the modes of functioning and consumers' engagement in three militant groups that promote alternative food systems, in the fields of responsible consumption, fair trade and contracts between producers and consumers, we show that the consumer role remains central. The organisations studied need to explicitly place themselves in opposition to a specific version of this consumer role, based on a form of direct lack of responsibility stemming from the modes of functioning of globalised systems. These groups highlight the fact that, by gradually removing consumers from the problems of production, globalised food systems have made them relatively unaware of the negative externalities produced upstream. Raising their consciousness is therefore not aimed immediately at transforming the consumer into an informed citizen; it should above all enable consumers to be enlightened, that is, involved in networks that enable them to grasp the implications of production and distribution, whether these are environmental, concern the sustainability of certain economic activities or concern the working conditions involved. In other words, it is through consumer practices that citizens' awareness must be expressed. The various trade systems set up by the organisations studied here are in this respect places of recruitment for political engagement but also, above all, places of recruitment of consumers. The pivotal position of consumption in these forms of political expression is perceived particularly well in the case of the organisation promoting engaged consumption, not only because most of its members are themselves part of specific supply chains but also because they are seeking guidelines for their own consumption practices over and above any form of more collective political engagement. The citizen role is not constructed to the detriment or even against that of the consumer; on the contrary, it relies on it to a large extent. Consumers and with them a certain consumerist logic cannot entirely disappear from these activist groups, of which they are clearly the mainstay.

\section{Notes}

* Corresponding author.

I ConsoResp is a pseudonym.

2 In French circuit court means a short supply chain but also evokes the cultural arena of movie-making and especially documentaries.

\section{Acknowledgements}

This work was carried out with the financial support of the Agence Nationale de la Recherche - (the French National Research Agency) under the programme 'Agriculture and Sustainable Development', in the 'Consumers' Groups and Sustainable Consumption' project. 


\section{References}

Adorno, T. and M. Horkheimer (I974) La dialectique de la raison (Paris: Gallimard)

Allen, P., M. FitzSimmons, M. Goodman and K. Warner (2003) Shifting plates in the agrifood landscape: the tectonics of alternative agrifood initiatives in California. Journal of Rural Studies i9 (I) pp. 6I-75

Baudrillard, J. (I968) Le système des objets (Paris: Gallimard)

Breen, T.H. (2004) The markeplace of revolution: how consumer politics shaped American independance (New York: Oxford University Press)

Cohen, L. (2003) A consumers' republic: the politics of mass consumption in postwar America (New York: Alfred A. Knopf)

Daunton, M. and M. Hilton (200I) The politics of consumption. Material culture and citizenship in Europe and America (Oxford: Berg)

Daviron, B. and S. Ponte (2005) The coffee paradox: global markets, commodity trade and the elusive promise of development (London: Zed Books)

Dubuisson-Quellier, S. and J. Barrier (2007) Protester contre le marché: du geste individuel à l'action collective. Le cas du mouvement anti-publicitaire. Revue Française de Science Politique 57 (2) pp. 209-237

Dubuisson-Quellier, S. and C. Lamine (2004) Faire le marché autrement. L'abonnement à un panier de fruits et légumes comme forme d'engagement politique des consommateurs. Sciences de la Société 62 (XX) pp. I45-168

Dubuisson-Quellier, S. and C. Lamine (2008) Consumers' involvement in fair trade and local food systems: delegation and empowerment regimes. GeoJournal 73 (I) pp. 55-65

Furlough, E. and A. Strikwerda (I99I) Consumer cooperation in France. The politics of consumption I834-I930 (Cornell, NY: Cornell University Press)

Glickman, L.B. (2006) 'Through the medium of their pocket': sabbatarianism, free produce, non intercourse and the significance of 'early modern' consumer activism. Pp. 2I-36 in A. Chatriot, M.-E. Chessel and M. Hilton eds, The expert consumer. Associations and professionals in consumer society (Farnham: Ashgate)

Goodman, D. (2002) Rethinking food production-consumption: integrative perspectives. Sociologia Ruralis 42 (4) pp. 27I-277

Goodman, D. (2003) The quality turn and alternative food practices: reflexions and agenda. Journal of Rural Studies i9 (I) pp. I-7

Goodman, D. (2004) Rural Europe redux? Reflections on alternative agro-food networks and paradigm change. Sociologia Ruralis 44 (I) pp. 3-I6

Goodman, D. and M. DuPuis (2002) Knowing food and growing food: beyond the productionconsumption debates in the sociology of agriculture. Sociologia Ruralis 42 (I) pp. 5-20

Goodman, M. (2004) Reading fair trade: political ecology, imaginary and the moral economy of fair trade foods. Political Geography 23 (7) pp. 89I-9I5

Hassanein, N. (2003) Practicing food democracy: a pragmatic politics of transformation. Journal of Rural Studies i9 (I) pp. 77-86

Holloway, L. and M. Kneafsey (2004) Producing-consuming food: closeness, connectedness and rurality in four alternative food networks. Pp. 262-282 in L. Holloway and M. Kneafsey eds, Geographies of rural cultures and societies (London: Ashgate)

Hudson, I. and M. Hudson (2003) Removing the veil? Commodity fetishism, fair trade and the environment. Organization and Environment I6 (4) pp. 4I3-430

Lamine, C. (2005) Settling shared uncertainties: local partnerships between producers and consumers. Sociologia Ruralis 45 (4) pp. 324-345

Le Velly, R. (2006) Le commerce équitable: des échanges marchands contre et dans le marché. Revue Française de Sociologie 47 (2) pp. 3I9-340

Le Velly, R. (2007) Is large-scale fair trade possible? Pp. 20I-2I5 in E. Zaccai ed., Sustainable consumption, ecology and fair trade (London: Routledge) 
Levkoe, C. (2006) Learning democracy through food justice movements. Agriculture and Human Values 23 (I) pp. 89-98

Littrell, M.A. and M.A. Dickson (I999) Social responsibility in the global market. Fair trade of cultural products (London: Sage)

Lockie, S. (2002) The invisible mouth: mobilizing the consumer in food productionconsumption networks. Sociologia Ruralis 42 (I) pp. 278-294

McAdam, D., S. Tarrow and C. Tilly (200I) Dynamics of contention (Cambridge: Cambridge University Press)

Marcuse, H. (I968) One-dimensional man (London: Sphere)

Mestre, C. (2004) Etude de l'impact de 25 ans de commerce équitable sur les producteurs du Sud partenaires. Rapport final (Paris: Fédération Artisans du Monde)

Micheletti, M. (2003) Political virtue and shopping. Individuals, consumerism, and collective action (New York: Palgrave)

Murray, D., L.T. Raynolds and P.L. Taylor (2003) One cup at a time: poverty alleviation and fair trade coffee in Latin America (Fort Collins: Colorado State University and Fair Trade Research Group)

Raynolds, L.T. (2002) Consumer/producer links in fair trade coffee networks. Sociologia Ruralis 42 (4) pp. 404-424

Renard, M.-C. (2005) Quality certification, regulation and power in fair trade. Journal of Rural Studies 2I (4) pp. 4I9-43I

Shreck, A. (2005) Resistance, redistribution and power in the Fair Trade initiative. Agriculture and Human Values 22 (I) pp. I7-29

Spaargaren, G. and S. Martens (2004) Globalisation and the role of citizen-consumers in environmental politics. Pp. 2II-245 in F. Wijen, K. Zoetman and J. Pieters eds, A handbook of globalization and environmental policy (Cheltenham and Northampton, MA: Edward Elgar)

Taylor, V. and N. Van Dyke (2005) Get up, stand up? Tactical repertories of social movements. Pp. 3-I6 in D. Snow, S. Soule and H. Kriesi eds, The Blackwell companion to social movements (Malden, MA: Blackwell)

Tilly, C. (2006) Regimes and repertoires (Chicago, IL: University of Chicago Press)

Trentmann, F. (200I) Bread, milk and democracy: consumption and citizenship in the $20^{\text {th }}$ century Britain. Pp. I29-I63 in M. Daunton and M. Hilton eds, The politics of consumption. Material culture and citizenship in Europe and America (Oxford: Berg)

Trentmann, F. (2007) Before fair trade: empire, free trade, and the moral economies of food in the modern world. Environment and Planning D 25 (6) pp. IO79-IIO2

Watts, D.C.H., B. Ilbery and D. Maye (2005) Making reconnections in agro-food geography: alternative systems of food provision. Progress in Human Geography 29 (I) pp. 22-40

Whatmore, S. (2002) Hybrid geographies. Natures cultures spaces (London: Sage)

Whatmore, S. and L. Thorne (I997) Nourishing networks: alternative geographies of food. Pp. 287-230 in D. Goodman and M. Watts eds, Globalising food: agrarian restructuring and global restructuring (London: Routledge)

Wilkins, J. (2005) Eating right here: moving from consumer to food citizen. Agriculture and Human Values 22 (3) pp. 269-273

Sophie Dubuisson-Quellier*

Centre de Sociologie des Organisations (CNRS-Sciences Po)

19 rue Amélie 75007 Paris

France

e-mail: s.dubuisson@cso.cnrs.fr 
Claire Lamine

Domaine de Montfavet 84000

Avignon

France

e-mail: clamine@grignon.inra.fr

Ronan Le Velly Montpellier SupAgro

UMR Innovation

2 place Viala, 34000

Montpellier

France

e-mail: levelly@supagro.inra.fr 